\title{
The Influence of Calcium Carbonate Grain Coatings on Contaminant Reactivity in Vadose Zone Sediments
}

(Project Number: 70121)

\section{Principal Investigator}

John M. Zachara

Pacific Northwest National Laboratory

P.O. Box 999, MSIN K8-96

Richland, WA 99352

509-376-3254 (phone)

509-376-3650 (fax)

mailto:john.zachara@pnl.gov

\section{Co-Investigators}

Scott Chambers

Pacific Northwest National Laboratory

P. O. Box 999, MSIN K8-93

Richland, WA 99352

509-376-1766 (phone)

509-376-5106 (fax)

sa.chambers@pnl.gov

Gordon E. Brown, Jr.

Stanford University

Stanford, CA 94305

650-723-9168 (phone)

650-725-2199 (fax)

gordon@pangea.stanford.edu

Carrick M. Eggleston

University of Wyoming

P.O. Box 3006

Laramie, WY 82071

307-766-6769 (phone)

307-766-6679 (fax)

mailto:carrick@uwyo.edu 


\section{Research Objective}

The primary objective of this project is to investigate the role of calcium carbonate grain coatings on adsorption and heterogeneous reduction reactions of key chemical and radioactive contaminants in sediments on the Hanford Site. Research will ascertain whether these coatings promote or discourage contaminant reaction with sediment mineral particles, and whether calcium carbonate phases resulting from waste-sediment reaction sequester contaminants through coprecipitation. The research will provide new conceptual models of contaminant reaction/retardation processes in Hanford sediments (for ${ }^{90} \mathrm{Sr}^{2+}$ and $\mathrm{Cr}(\mathrm{VI}) \mathrm{O}_{4}{ }^{2-}$ primarily) and improved geochemical models to forecast the future behavior of in-ground contaminants.

\section{Research Progress and Implications}

This project was initiated in fiscal year 1999 and is in its final year. Two primary research activities have been undertaken: 1) Characterization of ${ }^{90} \mathrm{Sr}^{2+}$ adsorption and exchange in pristine and contaminated calcareous Hanford sediments and 2) investigation of the role of calcium carbonate grain coatings on the heterogeneous reduction of $\mathrm{Cr}(\mathrm{VI}) \mathrm{O}_{4}{ }^{2-}$ by magnetite in model and sediment systems.

\section{Characterization of Strontium Adsorption and Exchange}

The ion exchange behavior of $\mathrm{Sr}^{2+}$ was studied in pristine, calcareous sediments in both $\mathrm{Na}$ and Ca electrolytes. The sediment samples were drawn from Hanford's B-BX-BY and T-TX-TY tank farms. Strontium adsorption in both systems displayed strong dependence on electrolyte concentration, consistent with an ion exchange process. The sand-textured sediments exhibit a small cation exchange capacity (approximately $10^{-5} \mathrm{eq} / \mathrm{g}$ ) resulting from the presence of detrital layer silicates. A multicomponent cation exchange model ( $\mathrm{Na}-\mathrm{Ca}-\mathrm{Sr}$ ) was developed for the entire data set that includes three ion exchange selectivity coefficients $\mathrm{K}_{\mathrm{Na}-\mathrm{Sr}}, \mathrm{K}_{\mathrm{Ca}-\mathrm{Sr}}$, and $\mathrm{K}_{\mathrm{Na}-}$ $\mathrm{Ca}$ (where $\mathrm{K}=$ the Vanselow selectivity coefficient) and the measured cation exchange capacities. Because the Hanford sediments contain appreciable ion-exchangeable ${ }^{86 / 87} \mathrm{Sr}^{2+}$, the adsorption process of contaminant ${ }^{90} \mathrm{Sr}^{2+}$ (which is typically present at 3 to 4 orders of magnitude lower concentration than indigenous ${ }^{86 / 87} \mathrm{Sr}^{2+}$ ) is one of isotopic exchange with the native $\mathrm{Sr}$ pool. The ${ }^{90} \mathrm{Sr}^{2+}-\mathrm{K}_{\mathrm{d}}$ is therefore controlled by the $\mathrm{K}_{\mathrm{d}}$ of the indigenous $\mathrm{Sr}$ pool, which, in turn, is predictable from our developed multicomponent cation exchange model. Adsorption experiments with ${ }^{86 / 87 / 90} \mathrm{Sr}^{2+}$ are currently being performed to document the predictability of these relationships with water compositions characteristic of different Hanford waste-release scenarios.

In other experiments, we have studied the mineralogic association of sorbed ${ }^{90} \mathrm{Sr}^{2+}$ and its desorption kinetics from contaminated sediments collected beneath leaked tank B-110 in Hanford's B tank farm complex. The waste stream leaked to these sediments was from the 
Sr-recovery process. We have succeeded in isolating ${ }^{90} \mathrm{Sr}^{2+}$-containing particles from the sediments (Figure 1) and now are characterizing these in detail using various forms of electron microscopy. We have contacted one sediment sample from the B-110 borehole that contained approximately $10,000 \mathrm{pCi} / \mathrm{g}$ of sorbed ${ }^{90} \mathrm{Sr}^{2+}$ with various electrolytes intended to desorb

- ion-exchanged ${ }^{90} \mathrm{Sr}^{2+}\left(0.01,1\right.$, and $\left.5 \mathrm{~mol} / \mathrm{L} \mathrm{NaNO}_{3} ; 0.05 \mathrm{~mol} / \mathrm{L} \mathrm{Ca}\left(\mathrm{NO}_{3}\right)_{2}\right)$

- coprecipitated ${ }^{90} \mathrm{Sr}^{2+}(1 \mathrm{~mol} / \mathrm{L} \mathrm{NaOAc}$ at $\mathrm{pH} 5 ; 0.5 \mathrm{~mol} / \mathrm{L} \mathrm{HCl})$ (Figure 2).
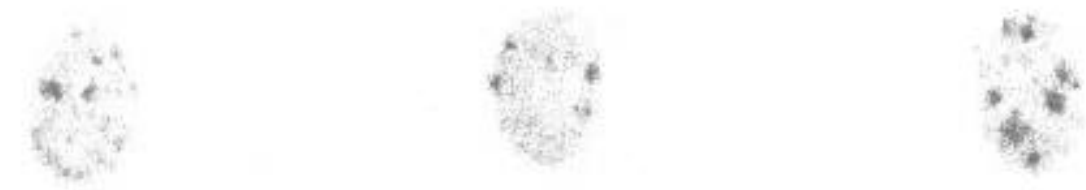

Figure 1. Samples of B-110 sediment were mounted on TEM stubs and imaged by phosphorluminescence. The dark areas are mineral grains or aggregate containing ${ }^{90} \mathrm{Sr}$. These grains were imaged by scanning electron microscopy and then were selectively removed for detailed mineralogic characterization and spatial Sr analysis.

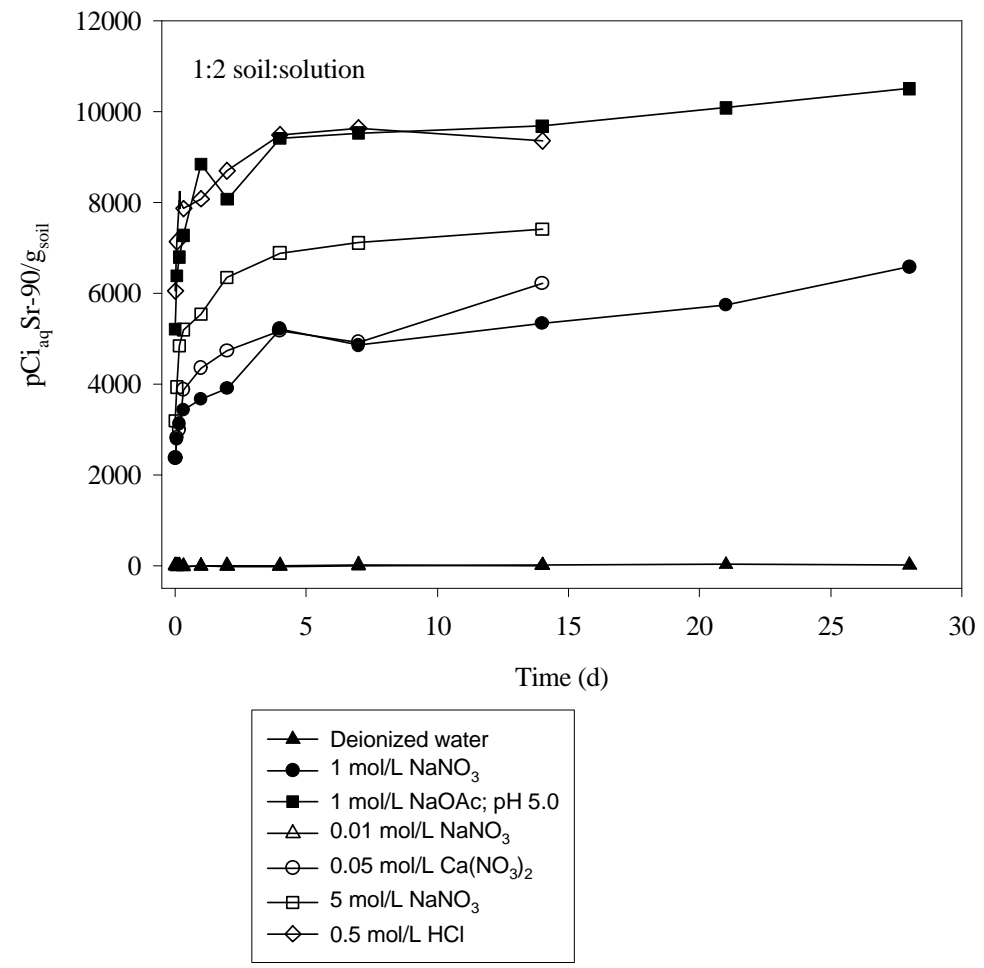

Figure 2. Time-dependent desorption of ${ }^{90} \mathrm{Sr}$ from contaminated B-110 sediment. ${ }^{90} \mathrm{Sr}$ was released to the sediment over 30 years ago in the form of a Sr recovery waste containing $\mathrm{Na}-\mathrm{HCO}_{3}$ and complexants. Extraction with 0.01 , 1 , and $5 \mathrm{~mol} / \mathrm{L} \mathrm{Na}$ and $0.05 \mathrm{~mol} / \mathrm{L}\left(\mathrm{Ca}\left(\mathrm{NO}_{3}\right)_{2}\right.$ removes inexchangeable ${ }^{90} \mathrm{Sr}$, while $\mathrm{NaOAc}$ at $\mathrm{pH} 5$ and $0.5 \mathrm{~mol} / \mathrm{L} \mathrm{HCl}$ dissolve host carbonate phases as well. 
The experiments have demonstrated that approximately $75 \%$ of the sorbed ${ }^{90} \mathrm{Sr}^{2+}$ is associated with the exchange complex, and $25 \%$ is associated with carbonate grain coatings that have resulted from waste-sediment reaction. These data now are being modeled with our multicomponent exchange model linked with a precipitation model. Collectively, these results provide a basis for predicting the geochemical behavior of ${ }^{90} \mathrm{Sr}^{2+}$ in various waste streams and subsurface sediments at the Hanford site.

\section{Investigation of Calcium Carbonate Grain Coatings}

The growth of complete calcium carbonate overlayers on synthetic magnetite (001) surfaces was accomplished by a biomineralization approach termed the polymer-induced liquid precursor (PILP) method. During this solution-based approach, poly-aspartate coats the magnetite surface and acts as a surfactant upon which primarily vaterite nucleates as a continuous film. An atomic force microscopy micrograph taken during early growth stages displayed a beta-sheet-like layer, reminiscent of poly-aspartate, with a carbonate overlayer nucleating atop. These calcium carbonate overlayers of vaterite crystal structure interfere with the reduction of $\mathrm{Cr}(\mathrm{VI}) \mathrm{O}_{4}{ }^{2-}$ at the magnetite-water interface. Films as thin as 20 to 25 angstroms inhibit the reduction of aqueous chromate throughout the $\mathrm{pH}$ range of 6 to 8 for exposures less than one hour (Figure 3).

Depending upon the carbonate film thickness, however, $\mathrm{Cr}(\mathrm{VI}) \mathrm{O}_{4}{ }^{2-}$ reduction did occur after

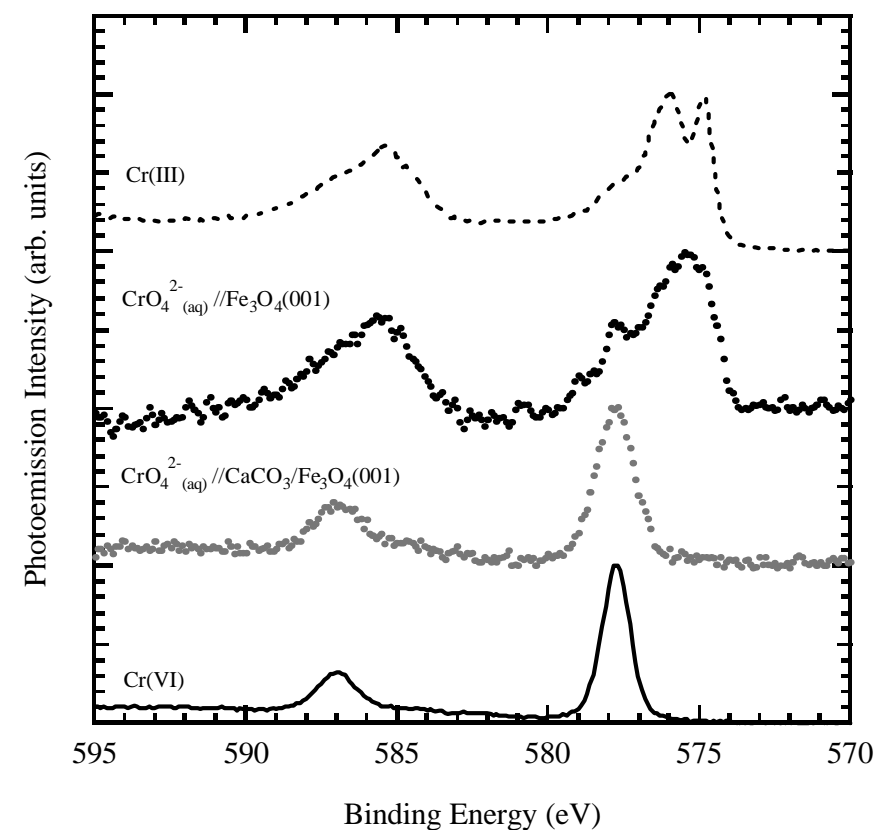

Figure 3. High-energy resolution $\mathrm{Cr} 2 p$ core-level spectra for synthetic magnetite(001) covered with calcium carbonate (gray) and not covered (black). Reference spectra for $\mathrm{Cr}(\mathrm{VI})$ and $\mathrm{Cr}(\mathrm{III})$ also are shown. 
extended reaction times due to dissolution of the calcium carbonate coatings. Surprisingly, however, secondary ion mass spectrometry (SIMS) analysis of samples from extended reaction showed that $\mathrm{Cr}$ was concentrated on the magnetite surface in areas of high carbon and less so in areas of high $\mathrm{Fe}$ content. This was puzzling until the experiment was performed in which the $\mathrm{Cr}(\mathrm{VI}) \mathrm{O}_{4}{ }^{2-}$ solution was also saturated with calcium carbonate. Expecting a lower dissolution rate of the coating due to a saturated solution and less $\mathrm{Cr}(\mathrm{VI}) \mathrm{O}_{4}{ }^{2-}$ reduction, we found, in contrast, that there was a significant $\mathrm{Cr}$ (III) photoemission signature. This was due to photoreduction of $\mathrm{Cr}(\mathrm{VI})$ to $\mathrm{Cr}(\mathrm{III})$ in the presence of adventitious carbon during analysis in the $\mathrm{x}$-ray photoemission chamber.

These findings provide a clear explanation for why $\mathrm{Cr}(\mathrm{VI})$ and $\mathrm{Tc}(\mathrm{VII})$ are stable valence states in the Hanford subsurface, in spite of the presence of significant magnetite and ilmenite in the sediments. Calcium carbonate grain coatings prevent heterogeneous reduction.

\section{Planned Activities}

Being well on in the last funded year of the project, most of our remaining activity is focused on publication of results. Some lingering experimentation with the ${ }^{90} \mathrm{Sr}^{2+}$-containing B-110 sediments and magnetite isolated from the Hanford sediment will continue to completion in the remaining months of fiscal year 2002. Some of our research results from the B-110 sediments will be incorporated into a Corrective Action Assessment Report for the B-BX-BY Tank Farms in July, thereby providing key scientific support for an important decision milestone at the Hanford Site.

\section{Information Access}

Droubay T and SA Chambers. 2001. Surface-sensitive Fe 2p photoemission spectra for alpha$\mathrm{Fe}_{2} \mathrm{O}_{3}(0001)$ : The influence of symmetry and crystal-field strength - Art. No. 205414. Physical Review B 6420(20):5414-+.

Droubay T and SA Chambers. 2002. Influence of Calcium Carbonate Coatings on Aqueous Hexavalent Chromium Reduction by $\mathrm{Fe}_{3} \mathrm{O}_{4}(001)$. Surface Science. Submitted.

Zachara JM, P Lichtner, and SC Smith. 2002. Ion exchange of $\mathrm{Sr}^{2+}$ in calcareous subsurface sediment and isotopic exchange of ${ }^{90} \mathrm{Sr}^{2+}$ as a retardation mechanism. Geochimica et Cosmochimica Acta. Submitted.

Zachara JM, P Lichtner, and SC Smith. 2002. Mineralogic residence and desorption kinetics ${ }^{90} \mathrm{Sr}^{2+}$ from contaminated subsurface sediments. Environmental Science and Technology. Submitted. 